\title{
Rule - based Fault Diagnosis Expert System for Wind Turbine
}

\author{
Xiao-Wen DENG ${ }^{1}$, Qing-Shui GAO ${ }^{1}$, Chu ZHANG ${ }^{1}$, Di HU ${ }^{2, a}$ and Tao YANG ${ }^{2}$ \\ ${ }^{1}$ Electric Power Research Institute of Guangdong Power Grid Co., Ltd., Guangzhou 510600, China \\ ${ }^{2}$ School of Energy and Power Engineering, Huazhong University of Science \& Technology, Wuhan 430074, China
}

\begin{abstract}
Under the trend of increasing installed capacity of wind power, the intelligent fault diagnosis of wind turbine is of great significance to the safe and efficient operation of wind farms. Based on the knowledge of fault diagnosis of wind turbines, this paper builds expert system diagnostic knowledge base by using confidence production rules and expert system self-learning method. In Visual Studio 2013 platform, C \# language is selected and ADO.NET technology is used to access the database. Development of Fault Diagnosis Expert System for Wind Turbine. The purpose of this paper is to realize on-line diagnosis of wind turbine fault through human-computer interaction, and to improve the diagnostic capability of the system through the continuous improvement of the knowledge base.
\end{abstract}

\section{Introduction}

With more attention paid to the energy security, ecological environment, climate change and other issues, to accelerate the development of wind power has become the consensus of the international community to promote the transformation of energy development, to cope with global climate change and concerted action. According to statistics, by the end of 2015 the global wind power installed capacity of 432 million kilowatts, spread over the world in more than and 100 countries and regions [1]. Global wind power installed capacity continues to grow, fault diagnosis technology has gradually become a hot topic in the field of wind power.

For the working life of 20 years of the unit, the operation and maintenance costs generally account for the entire wind farm's total investment of $10 \% \sim 15 \%$, while for the offshore wind farm, the overall ratio of up to $20 \% \sim 25 \%$ [2]. Statistics show that the determining time for the fault diagnosis takes up $70 \%$ to $90 \%$ of the total time, while the repair time takes up only about $10 \%$ to $30 \%$ [3]. Therefore, efficient and accurate fault diagnosis technology is an important way to ensure the economic and safe operation of wind turbine.

There are many fault diagnosis systems have been successfully applied in many kinds of technical processes to improve operation reliability and safety. Yang introduced a Web-oriented expert system for gear box in wind turbine using the fault tree model [4]. Yang developed an aviation fault diagnosis expert system, the reasoning machine based on the combination of fault tree and generalized regression neural network [5]. Yao presented an engine rotor fault diagnosis method based on random forests, that the failures be diagnosed timely and effectively to keep the engine in normal operation [6]. By using the fast diagnosis ability of expert system, the wind farm can greatly improve the efficiency of diagnosis.

\footnotetext{
${ }^{a}$ Corresponding author: 18140662310@163.com
} 
This paper applies a rule based expert system [7] on wind turbine fault diagnosis, in order to make timely, accurate diagnosis for wind turbine and provide timely solutions. First, summarize the wind turbine fault symptoms and solutions, and the relationship between them is expressed in the form of rules. Then choose the C\# language in the Visual Studio 2013 platform, use ADO.NET technology to access the database to establish the expert system. In this way, it can not only meet the requirements of rapid response to wind turbine fault diagnosis, but also prevent the emergence of human error, the valuable experience of experts can be retained to prevent lost, too.

Section 2 discusses the structure of the rule-based expert system, and the common faults of wind turbine and solutions. Section 3 discusses the rule-based wind turbine fault diagnosis expert system, mainly the establishment of the knowledge base and reasoning machine. Finally, Section 4 concludes.

\section{The expert system based on production rules}

Expert system is composed of man-machine interface (divided into user interface and development interface), knowledge acquisition module, knowledge base, reasoning machine, interpreter and comprehensive database. Experts or knowledge engineers in the development interface in the development of expert systems, increase, modify or delete faults, signs and rules, signs and rules stored in the diagnostic knowledge base, failure and other related information stored in the integrated database. The user in the user interface for rule-based diagnosis, the symptoms will be extracted into the rules of diagnostic module, the inference engine work to draw diagnostic conclusions, the interpreter of the system's reasoning conclusion to explain, feedback to the user. Rule based expert system schematic is shown in Figure 1.

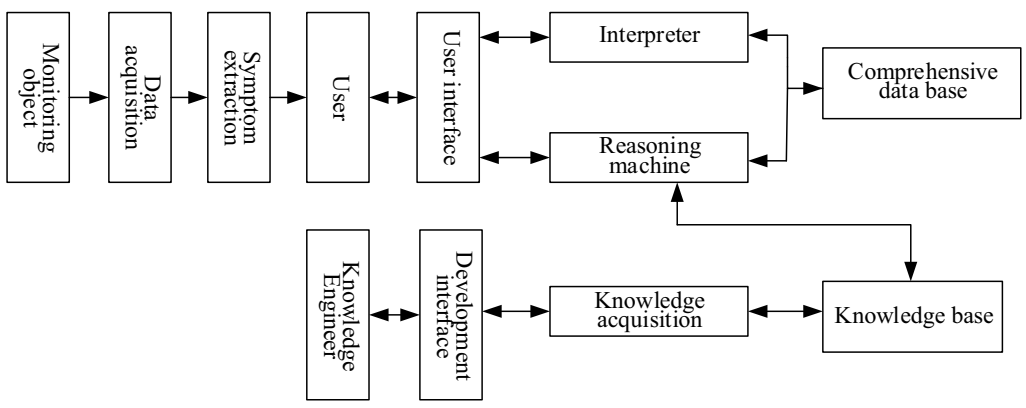

Figure 1. Rule based expert system schematic

The expert system based on production rules transforms the expert's diagnosis experience and knowledge into the production rule, and carries on the fault diagnosis through certain reasoning mechanism. It can clearly express the causality of the fault, and it is easy to add and modify [8]. Monsef $\mathrm{H}$ uses PROLOG to develop a rule-based fuzzy expert system for fault diagnosis of power system [9]. Soe S. M. M established a rule-based expert system for fault management of network devices [10]. Liu used depth-first search strategy as a control strategy, a rule-based fault diagnosis expert system is built, which solves the problem that some faults will be missed due to conflict in the reasoning process [11].

Production rules is composed of the first term If and the second term Then. The If is part of one or more conditions, conditions of each sub by logical connectives (and, or) composed of different combinations. The latter part of Then is one or more rear action should be taken or the conclusion, the premise condition is true conclusion. Rule reasoning is derived from If's preconditions Then the rear conclusion.

"If $<$ Precondition true $>$ then $<$ Generate action $>$ or $<$ Draw a conclusion $>$ "

The rule is the core of the expert system. The rule of good or bad determines the diagnosis effect of the expert system. It is necessary to improve the fault diagnosis and fault indication before 
establishing the diagnosis rule of the expert system. According to the fault history data of the wind turbine, the faults mainly focus on the key parts such as gear box, generator, low speed shaft, high speed shaft and blade. Now only list part of the common faults, fault phenomena and their causes of failure, as shown in Table 1.

Table 1. Part of the common fault in wind turbine

\begin{tabular}{|c|c|c|}
\hline Fault & Fault phenomena & Causes of failure \\
\hline $\begin{array}{l}\text { High speed } \\
\text { shaft unbalance }\end{array}$ & $\begin{array}{l}\text { 1. The spectrum of its } 1 X \text { (X said } \\
\text { multiplier) based } \\
\text { 2. Radial runout } \\
\text { 3. Amplitude increases with } \\
\text { increasing speed } \\
\text { 4. Axis orbit for a more round or oval }\end{array}$ & $\begin{array}{l}\text { Rotor of the rotating machine due to the } \\
\text { material density distribution, assembly } \\
\text { factors, processing errors and movement } \\
\text { of the erosion and deposition and other } \\
\text { factors led to the center of mass and the } \\
\text { rotation center there is a certain degree of } \\
\text { eccentricity. }\end{array}$ \\
\hline $\begin{array}{l}\text { High speed axis } \\
\text { misalignment }\end{array}$ & $\begin{array}{l}\text { 1. The spectrum is its } 1 \mathrm{X}, 2 \mathrm{X} \text { or } \\
\text { higher harmonic } \\
\text { 2. Axial vibration } \\
\text { 3. The amplitude does not vary with } \\
\text { the speed } \\
\text { 4. Axis trajectory was banana-shaped } \\
\text { or 8-shaped }\end{array}$ & $\begin{array}{l}\text { Installation in the construction of the } \\
\text { ultra-poor, the thermal expansion of } \\
\text { housing, chassis deformation or } \\
\text { displacement, high-speed shaft bending. }\end{array}$ \\
\hline $\begin{array}{l}\text { High speed } \\
\text { shaft bending }\end{array}$ & $\begin{array}{l}\text { 1. The spectrum is its } 1 \mathrm{X}, 2 \mathrm{X} \text { or } \\
\text { higher harmonic } \\
\text { 2. When the rotor speed is fixed, the } \\
\text { vibration amplitude is fixed }\end{array}$ & $\begin{array}{l}\text { The bending of the shaft is permanent } \\
\text { bending and temporary bending. The } \\
\text { former is mainly caused by design and } \\
\text { manufacturing defects, improper long- } \\
\text { term parking methods, etc. The latter is } \\
\text { mainly overloaded but can be recovered. }\end{array}$ \\
\hline $\begin{array}{l}\text { High speed } \\
\text { shaft parts } \\
\text { loosening }\end{array}$ & $\begin{array}{ll}\text { 1. } & \text { The spectrum is its } 1 \mathrm{X} \text { and } \\
\text { harmonic } \\
\text { 2. Vertical vibration greater } \\
\text { 3. Vibration amplitude is not fixed }\end{array}$ & $\begin{array}{l}\text { The fastener is not fastened, and the } \\
\text { fastener is loose or the fastener is } \\
\text { damaged under the vibration of the base. }\end{array}$ \\
\hline $\begin{array}{l}\text { High-speed } \\
\text { shaft rubbing }\end{array}$ & $\begin{array}{l}\text { 1. Most of the spectrum is its } 1 \mathrm{X} \\
\text { component, there are harmonics, } \\
\text { sub synchronous and natural } \\
\text { frequency components } \\
\text { 2. Axis trajectory was banana-shaped } \\
\text { or 8-shaped }\end{array}$ & $\begin{array}{l}\text { The speed may be too fast or the internal } \\
\text { temperature of the wind turbine may } \\
\text { change abruptly or the distance between } \\
\text { the rotating parts and the fixed parts may } \\
\text { be too small or the part offsets may cause } \\
\text { friction. }\end{array}$ \\
\hline Blade fracture & $\begin{array}{l}\text { 1. The spectrum is } \mathrm{fz}=\mathrm{ft} \times \mathrm{Z} \\
\mathrm{ft} \text {-impeller frequency } \\
\text { Z-Number of impeller blades }\end{array}$ & $\begin{array}{l}\text { Long-term outdoor harsh environment of } \\
\text { the work, the blade surface will be } \\
\text { fouling or ice leaves, so that uneven stress } \\
\text { due to the blade load fatigue crack, and } \\
\text { ultimately fracture. }\end{array}$ \\
\hline
\end{tabular}

\section{Realization of fault diagnosis expert system for wind turbine}

Expert system development using C \# has many advantages [12]. Therefore, the system is based on Visual Studio 2013 platform to select C\# language for software development, using ADO.NET technology to access the database. In this section, the article will show how to use $\mathrm{C} \#$ to represent the knowledge of fault diagnosis as a computer - recognizable form, to build the knowledge base of fault 
diagnosis, and the forward reasoning method based on precise reasoning mechanism is adopted in the reasoning mechanism. Three important aspects of expert system: knowledge representation, knowledge acquisition, reasoning model. Finally, the article will show the man-machine interface.

\subsection{Knowledge representation}

In actual wind farms, the difference between different wind turbines increases the uncertainty relationship between fault symptoms and faults. In order to make the expert system have the ability to deal with these uncertainty information, and can make the corresponding judgment when the information is not very complete, the expert system in this system adopts the production rule based on the confidence degree, and uses the confidence degree to describe the degree of symptom determination.

A rule is a knowledge entity, itself has the function of advisory reasoning, which is implemented by the Query function of the rule class. A rule is a node in a chain of rules, and a chain of rules consists of a knowledge base.

Confidence-based production rule representation is as follows:

If $R 1(W 1, K 1)$ and $R 2(W 2, K 1)$ and... and $R n(W n, K n)$

Then $T$ With $(C F, K)$

$R l, R 2 \ldots R n$ represents the premise of a rule, also known as the failure symptom;

$W 1, W 2 \ldots, W n$ is the weight of each precondition of rules;

$K 1, K 2 \ldots K n$ is the threshold of confidence, prerequisite rules of each;

$T$ is the rule conclusion; $C F(C F \in 0 \sim 1)$ is the rules of the credibility of the conclusion

$K(K=0 \sim 1)$ is a rule established threshold, only when the true value is greater than or equal to $K$ rules, this rule is activated.

For example, the design of a wind turbine generator shaft unbalance failure based on the confidence of the production rules, which are as follows:

If the spectrum (1X-based, spectrum into fir tree) Weight (0.4) Confidence threshold (0.8)

And phase (stable) weight (0.1) confidence threshold (0.8)

And Axis Trajectory (Oval) Weight (0.2) Confidence Threshold (0.8)

And rotation feature (forward movement) Weight (0.1) Confidence threshold (1)

And vibration direction (radial) weight (0.05) Confidence threshold (1)

And the critical vibration (the difference between horizontal and vertical direction is not significant) Weight (0.05) Confidence threshold (0.8)

And other (vibration varies with speed) Weight (0.1) Confidence threshold (1)

Then the rotor imbalance With $(C F=0.98, K=0.7)$

In the expert system based on the confidence production rule, we need to determine the confidence of the symptom in the fault diagnosis. If the symptom is deterministic, the user only needs to give an affirmative answer, which sets the confidence of the fault symptom to 1 ; in most cases, however, the symptom does not have an exact quantitative value, and the user can determine a confidence level based on what is observed.

\subsection{Knowledge acquisition}

The knowledge acquisition in this system is divided into two ways: one is manual input, the knowledge is input by the knowledge engineer in the development interface, and the other is the automatic learning of the machine, which can acquire the knowledge through the modification of the fault diagnosis process.

Two self-learning methods are designed in this system, which can self-study in the diagnosis process, improve the diagnosis rules and improve the correct rate of fault diagnosis, and finally achieve a better diagnostic effect on wind turbine fault diagnosis. The system self-learning process shown in Figure 2. 
1. When the selected symptom matches a diagnostic rule successfully, it automatically increases the confidence level of the diagnostic rule. The new confidence level of the diagnostic rule is determined by the following equation (1), where $\mathrm{k}$ is a coefficient, and the smaller $\mathrm{k}$, the faster the confidence increases. If the current trustworthiness of the rule is smaller, the more the rule credibility increases after the match is successful.

$$
C F_{\text {new }}=C F+\frac{1-C F}{k}
$$

2. When the selected symptom does not match the rule, the system will remind you whether to add a new diagnostic rule. If you choose to add a new rule, you need to select a fault as the diagnostic conclusion, and form a new rule together with the previously selected symptom to improve the expert system.

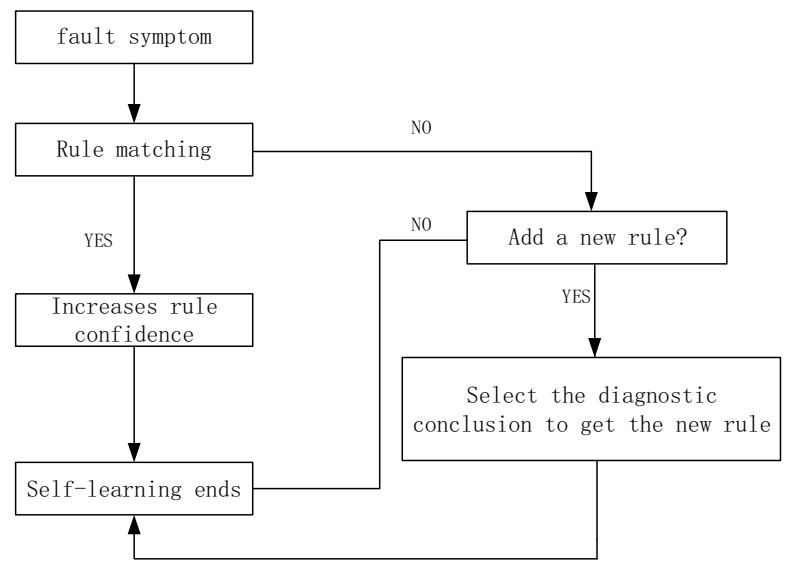

Figure 2. The system self-learning process

\subsection{Rreasoning model}

Expert system uses the reasoning model to solve the problem, so the reasoning model in the expert system is very important. The expert system in this system adopts forward reasoning. Fault diagnosis, through the parts monitoring parameters to determine its fault symptoms, fault diagnosis interface to select the appropriate symptoms, and then by the expert system to get the fault diagnosis results.

In this paper, the expert system's forward reasoning process is presented by the rule of "rotor unbalance", as shown in Table 2.

1. According to the symptom matching rule

Match the entered symptoms with all the rules one by one. If only one of these symptoms exists in a rule, the true value of the rule is calculated.

2. Calculate the true value of each symptom (rule sub condition)

When the confidence level of the symptom is greater than its confidence threshold in the rule, the true value is 1 . When the confidence level is less than the confidence threshold, then the ratio of confidence level and confidence threshold is taken as the true value of the symptom. It is shown in Table 2.

3. Calculate the true value of the rule

The true value of the rule is determined by all the prerequisites in the rule. The calculation formula is as follows: 


$$
T=\left(\sum_{i=1}^{n} W_{i} \times T_{i}\right) * C F
$$

The $W_{i}$ is the weight of the corresponding prerequisites, $T_{i}$ is the true value of this symptom, and $C F$ is the credibility of the rule. In the above example, there are symptoms in the "rotor imbalance" this rule, then calculate the true value of this rule as follows:

$$
\begin{aligned}
T & =(0.4 \times 1+0.1 \times 1+0.2 \times 1+0.1 \times 1+0.05 \times 1+0.05 \times 1+0.1 \times 0.8) * 0.98 \\
& =0.9604
\end{aligned}
$$

4. Gives the fault diagnosis conclusion

It can be seen from the calculation that the true value 0.9604 of the "rotor unbalance" rule is greater than the activation threshold value 0.7 , so this rule is activated. Therefore, the selected symptom matches the "rotor imbalance" rule, and the system extracts the fault name and fault explanation related to this rule according to the diagnosis result and outputs to the diagnosis interface.

Table 2. The process of forward reasoning

\begin{tabular}{|l|c|c|c|c|c|}
\hline \multicolumn{1}{|c|}{ Rule "rotor imbalance" } & \multicolumn{2}{c|}{ Diagnosis } & Result \\
\hline \multicolumn{1}{|c|}{ Symptoms } & Weight & $\begin{array}{c}\text { Confidence } \\
\text { threshold }\end{array}$ & $\begin{array}{c}\text { Confidence } \\
\text { level }\end{array}$ & True value \\
\hline $\begin{array}{l}\text { spectrum (1X-based, } \\
\text { spectrum into fir tree) }\end{array}$ & 0.4 & 0.8 & 1.0 & 1.0 \\
\hline phase (stable) & 0.1 & 0.8 & 1.0 & 1.0 \\
\hline $\begin{array}{l}\text { Axis Trajectory (Oval) } \\
\text { rotation feature (forward } \\
\text { movement) }\end{array}$ & 0.2 & 0.8 & 1.0 & 1.0 & $\begin{array}{l}\text { T }>\mathrm{K} \\
\text { Rule is } \\
\text { activated }\end{array}$ \\
\hline $\begin{array}{l}\text { vibration direction (radial) } \\
\text { difference between (the } \\
\text { horizontal and vertical } \\
\text { direction is not significant) }\end{array}$ & 0.05 & 1.0 & 1.0 & 1.0 & 1.0 \\
\hline $\begin{array}{l}\text { other (vibration varies with } \\
\text { speed) }\end{array}$ & 0.05 & 0.8 & 1.0 & 0.8 \\
\hline \multicolumn{1}{|c|}{ CF=0.98 } & $\mathrm{K}=0.7$ & 1.0 & 0.8 & $\mathrm{~T}=0.9604$ \\
\hline
\end{tabular}

\subsection{The man-machine interface}

\subsubsection{Login interface}

The wind turbine fault diagnosis expert system can be accessed through the server. All operators enter the correct user name and password to enter the system's fault diagnosis interface, login interface shown in Figure 3. 


\section{Condition Monitoring and Fault Diagnosis System for Wind Turbine}

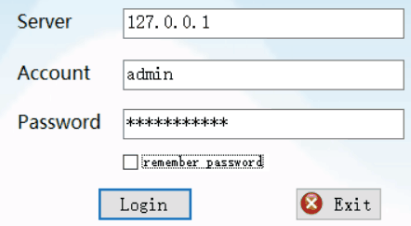

Figure 3. The Login interface

\subsubsection{Fault diagnosis interface}

After successfully logging into the system, click on the fault diagnosis button to enter the fault diagnosis module, fault diagnosis interface shown in Figure 4. Users can select the unit to be diagnosed, and then enter the fault symptom and the symptom of confidence, click the "Start Diagnosis" button, the system will automatically match the rules from the knowledge base to complete the fault diagnosis. In this interface, the system will automatically give the diagnosis of the credibility of the results and provide diagnostic details.

\section{Fault Diagnosis Expert System}

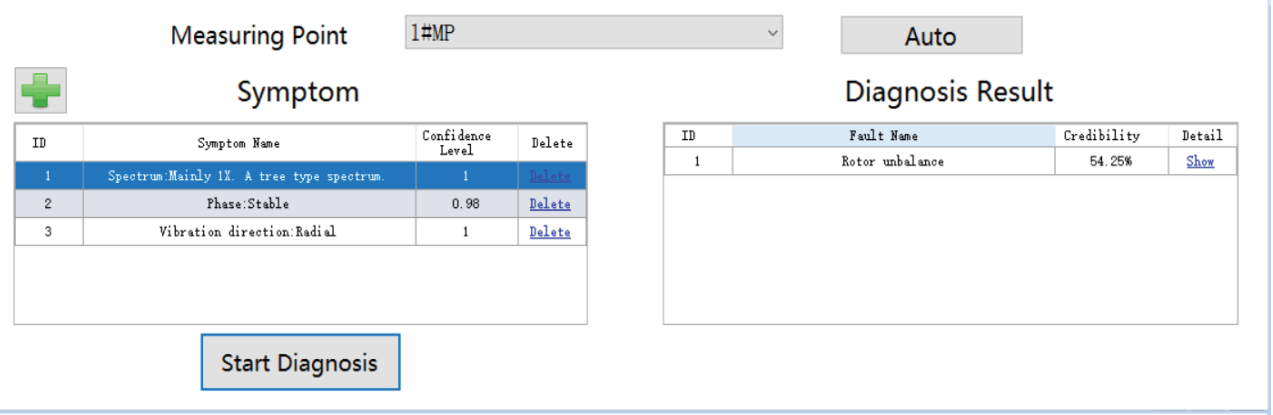

Figure 4. The Fault diagnosis interface

\subsubsection{Rules management interface}

Administrators can add, delete, and modify rules in the rule management interface. As shown in Figure 5, in this interface, the administrator can define the name of the rule, select the appropriate prerequisite, and set the diagnostic conclusion. In addition, the administrator can manually modify the priority of rule matching, the threshold of activation and the reliability of diagnostic results through 
historical diagnosis results, so as to improve the diagnostic knowledge base and improve the efficiency and accuracy of expert system diagnosis.

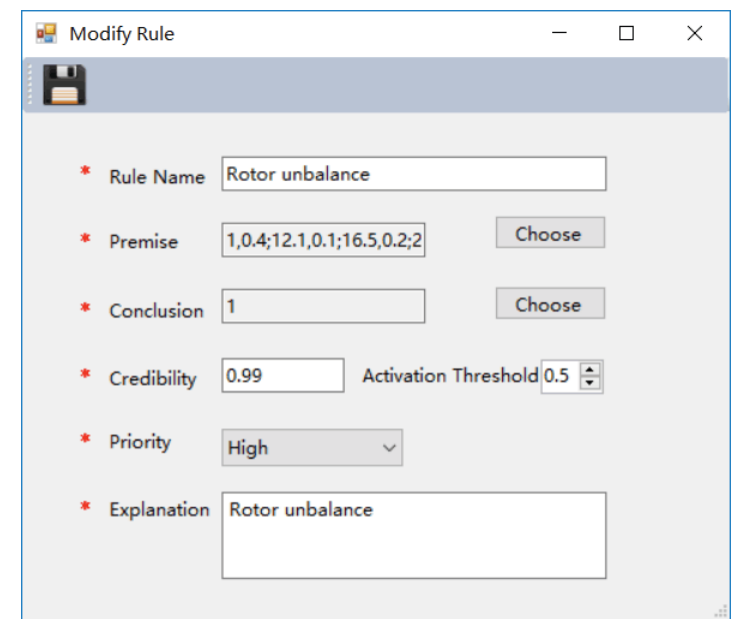

Figure 5. The Rules management interface

\section{Conclusion}

The development of computer science and artificial intelligence technology has greatly promoted the practical application of intelligent fault diagnosis technology. Based on the expert knowledge of wind turbine fault diagnosis, this paper designs a wind turbine fault diagnosis expert system based on production rules. In the process of establishing the knowledge base, a production rule based on confidence and an expert system self-learning method are designed, which can effectively increase the validity of the diagnosis result and expand the content of the knowledge base. In Visual Studio 2013 platform, we choose $\mathrm{C}$ \# language, and use ADO.NET technology to access the database, and realize the development of wind turbine fault diagnosis expert system. The system, in combination with the fault signal detection and processing technology, can identify the state of the given environment and fault analysis, and provide recommendations to solve the problem. With the continuous accumulation of wind turbine operation data, the knowledge of the system diagnosis knowledge base is improved by strengthening the communication with field experts and improving the efficiency and accuracy of system fault diagnosis.

\section{References}

1. National Energy Administration. "Wind power development 13th Five-Year plan" [EB/OL]. http://www.nea.gov.cn/2016-11/29/c_135867633.htm, November 29, 2016

2. B Lu, Y Li, Z Yang. A review of recent advances in wind turbine condition monitoring and fault diagnosis[C]//Power Electronics and Machines in Wind Applications, 2009. PEMWA 2009. IEEE. IEEE, 2009, 1-7 (2009)

3. W Yi, F Xiaoyun. Electric locomotive fault diagnosis expert system based on fault tree. Electric Locomotives \&Mass Transit Vehicles, 27, 35-36 (2004)

4. Y Zhiling, W Bin, D Xinghui, L Hao. Expert system of fault diagnosis for gear box in wind turbine[J]. Systems Engineering Procedia, 4,189-195(2012) 
5. L Yang, J Wang, G Zhang, $Z$ Ding. An expert system reasoning machine based on the combination of fault tree and generalized regression neural network[C]//ntelligent Control and Automation (WCICA), 2016 12th World Congress on.IEEE,1303-1306(2016)

6. Q Yao, J Wang, L Yang, S Haixia, Z Guigang. A fault diagnosis method of engine rotor based on Random Forests[C]//Prognostics and Health Management (ICPHM), 2016 IEEE International Conference on. IEEE,1-4(2016)

7. A Abraham. Rule-Based expert systems[J]. Handbook of measuring system design, (2005)

8. G Peixian, F Yongpeng. Research on the inherent defects of the integrated R \& D system based on rule based expert system [J]. Computer Measurement and Control, 19(7),1711-1714(2011)

9. H Monsef, A M Ranjbar, S Jadid. Fuzzy rule-based expert system for power system fault diagnosis[J]. IEE Proceedings-Generation, Transmission and Distribution, 144(2),186-192(1997)

10. S M M Soe, M P P Zaw. Design and implementation of rule based expert system for fault management[J]. World Academy of Science, Engineering and Technology, 48,34-39(2008)

11. L Jian, C Yichao, J Hong. Fault diagnosis method for general expert knowledge base based on rule $[\mathrm{J}]$. computer and digital engineering, 38(6),72-76(2010)

12. L Jianhua. Design and Implementation of Expert System[J]. Information Technology, 30(4),150152(2006) 